\title{
An Analysis of the Spring-to-Summer Transition in the West Central Plains for Application to Long Range Forecasting
}

\author{
Rosalie G. Newberry ${ }^{1}$, Anthony R. Lupo ${ }^{2 *}$, Andrew D. Jensen ${ }^{3}$, R. Antonio Rodriges Zalipynis ${ }^{4}$ \\ ${ }^{1} \mathrm{KXAN}-\mathrm{TV}$, Austin, TX/KOMU-TV, Columbia, MO, USA \\ ${ }^{2}$ Department of Soil, Environmental, and Atmospheric Science, University of Missouri, \\ Columbia, MO, USA \\ ${ }^{3}$ Department of Mathematics and Meteorology, Northland College, Ashland, WI, USA \\ ${ }^{4}$ Department of Software Engineering, Faculty of Computer Science, National Research University Higher \\ School of Economics, Moscow, Russia \\ Email: 'LupoA@missouri.edu
}

Received 10 December 2015; accepted 22 May 2016; published 25 May 2016

Copyright $(\subset 2016$ by authors and Scientific Research Publishing Inc.

This work is licensed under the Creative Commons Attribution International License (CC BY).

http://creativecommons.org/licenses/by/4.0/

c) (i) Open Access

\begin{abstract}
The spring-to-summer transition is of special importance in long range forecasting, as the general circulation transitions to a less energetic regime. This affects the Midwestern United States in a profound way, since agriculture is very sensitive to the variability of weather and climate. Beginning at the local scale, surface temperature observations are used from a representative station in the West Central Missouri Plains region in order to identify the shift from late spring to early summer. Using upper-air re-analyses as a supplement, the 500 -mb height observations are examined to find a spring-to-summer transition date by tracking the location of a representative contour. Each of these is used to identify spring-to-summer transition date and then statistical analysis is performed on this long-term data set. Finally, teleconnections, specifically the influence of El Niño Southern Oscillation (ENSO) and Pacific Decadal Oscillation (PDO), and blocking are examined in order to quantify interannual variability. It was found that examining these criteria, developed in an earlier study that covered a much shorter time period, produced similar statistics to this 68-year study of spring-to-summer transitions. It was also found that the onset of La Niña was associated with hotter summers in the region, a result first found in the earlier study, but this association was much stronger here.
\end{abstract}

\section{Keywords}

Interannual Variability, Summer Season Transitions, El Nino, Pacific Decadal Oscillation

\footnotetext{
"Corresponding author.
}

How to cite this paper: Newberry, R.G., Lupo, A.R., Jensen, A.D. and Zalipynis, R.A.R. (2016) An Analysis of the Spring-toSummer Transition in the West Central Plains for Application to Long Range Forecasting. Atmospheric and Climate Sciences, 6, 375-393. http://dx.doi.org/10.4236/acs.2016.63031 


\section{Introduction}

The West Central Plains, including Missouri, is a region that exhibits strong seasonality, and interannual and inter decadal variability. The transition between the cold and warm seasons is often difficult to forecast, and it also is indicative of a change to a less energetic weather regime [1] [2]. Seasonal transition is recognized as a problem in dynamic meteorology, but research on the Northern Hemisphere spring to summer transition is noted in fewer than ten academic research papers ([2], and references therein). It was noted, however, that more than 9000 articles appear in a search for “seasonal transitions” in the American Meteorological Society's online journals (http://www.journals.ametsoc.org). There are, however, other types of seasonal regime transitions that have been studied and are important from synoptic or storm-property point of view as well [3]-[5].

Recently, a diagnostic method based on the stability of the upper air flow as measured using enstrophy diagnostics [6] was shown to successfully identify the transition between high and low amplitude hemispheric-wide flow regimes [1] using data from as few as two 12-h time periods. The study of [1] used a quantity called the Wave Amplitude Index in order to identify these transitions using time series. Then, [2] used the Wave Amplitude Index to show that the spring to summer transition could be more gradual or quite abrupt in the west-central plains region. It is important to extend our knowledge in identifying these transitions, in order to improve the capability of long-range forecasting, which will in turn impact different sectors of Missouri's culture and economy.

The detection of the transition between spring and summer can be accompanied by a change in daily temperature and precipitation patterns. Spring is known to be mild and it is the season with the greatest total precipitation in the Midwest region, with the peak in total precipitation occurring in most places during May. The onset of the summer pattern, which is sometimes abrupt, is associated with a period of consistently high temperature, high humidity and dry periods interjected with fewer episodes of convective precipitation [2] [7]. Also, the 500 $\mathrm{hPa}$ geopotential height contours can be used as a measure of the amount of potential or in the case of kinetic energy a surrogate for energy in the atmosphere (e.g., [1] [2] [8]). By examining a change in the 500-mb height field over an extended period of time, periods of atmospheric excitation and relative mean energy states can be used as seasonal markers [8].

Two important teleconnections which have an influence on the seasonal conditions in the study region are El Niño Southern Oscillation (ENSO) and the Pacific Decadal Oscillation (PDO). Their phases and interactions have been shown to have unique impacts on regional temperature and precipitation regimes for the seasonal scale (e.g., [9]-[13]). Teleconnections, or the relationship of general circulation and climate anomalies at distances of thousands of kilometers, were first noted by Sir Gilbert Walker in the early twentieth century [14]. Recently, [15] looked at significant rainfall patterns in South America as a function of ENSO mode, noting that different ENSO phases were associated with a quasi-symmetric rainfall pattern. Also, [16] argued for the expansion of the idea of ENSO teleconnections into the Intra-Americas Seas, i.e. the Gulf of Mexico and the Caribbean Sea, citing that atmospheric ENSO patterns affect the two bodies of water in opposite ways. This is especially true for tropical cyclones (e.g. [17] [18]). Also, many researchers have focused on the impact ENSO has on the yearly monsoons, including Australian and Asian monsoons (e.g. [19] [20]).

Some applicable studies to this research, though, examined ENSO effects for North America. The primary mechanism for the influence of ENSO on the weather of North America is via its impact on the typical configuration of the Pacific-North American area jet stream. For example, [21] and [22] were among the first to examine the impact of ENSO over North America and the rest of the globe. Also, [23] examined land falling hurricanes in the US with respect to ENSO. Then, [24] utilized National Centers for Environmental Prediction/ National Center for Atmospheric Research (NCEP/NCAR) reanalysis data to demonstrate the connection between strong ENSO phases and upper-air data in North America, including 500-mb geopotential heights and 850-mb specific humidity. Additionally, [25] proposed that ENSO impacts may be bi-modal based on the primary ENSO genesis region. Specifically, [25] found that the ENSO impact on North America differs for an event that is an eastern Pacific versus a central Pacific ENSO event. Also, other researchers have coupled the North American ENSO effects with the impacts of PDO. Also, [26] examined dry and wet conditions in the U.S. Great Plains, demonstrating that ENSO and PDO coupling can intensify ENSO phases. Then [12] also found this impact, but they concentrated specifically on the Midwest to outline the regional effects of ENSO/PDO coupling. Another [27] investigated PDO and El Nino interactions and their impact on the temperature and precipitation regimes in the Amur River basin of far southeast Russia, including summer season transitions similar to [2]. 
The purpose of this study is based on the framework of the research published by [2] on the spring to summer transition in the West Central Plains and their interannual variability in the temperature regime. Their study, however, examined only 20 year period from 1981-2000 and focused on ENSO variability. This study [2] investigated daily temperature and precipitation patterns using data from Jefferson City, MO and also used nine cooperative National Weather Service sites as a quality control. They [2] also utilized $500 \mathrm{hPa}$ heights information in two ways; first to identify a minimum height requirement for the spring-to-summer transition date, and second as a surrogate for energy in the atmosphere using the [1] wave amplitude index. This research will examine interannual variability the temperatures of the region and the spring-to-summer transition over a longer time period than [2], and include an analysis of decadal variability with respect to the PDO and interactions with ENSO modes. While the relationship with ENSO seems to be relatively weak, a stronger connection is found in relation to the transition of ENSO phase [28].

\section{Data and Methods}

\subsection{Data}

The study of [2] examined spring-to-summer transitions using observational data over the period 1981-2000. This work expands the same data set, and the time period for this research is 1948 to 2015. The $500 \mathrm{hPa}$ heights are archived at the National Centers for Environmental Prediction/National Center for Atmospheric Research (http://www.esrl.noaa.gov/psd/data/reanalysis) [29]. These are a netCDF-based data set that can be used to display assimilated data from 1948 to the present. Also, [2] identified twenty summer transition dates. The mean, median and mode all fell in June; and only one date was selected in the months of May and July each (21 May, 1991 and 01 July, 2000). Then [2] examined temperatures and precipitation from April through September, their result allows this work to focus on the May through July period.

The statistical tests used in this study are found in standard statistical textbooks (e.g., [30] [31]). In order to test long-term linear trends, the analysis of variance (ANOVA) technique was used, which involves the F-test. A standard t-test was also used to test correlations for significance. Mean temperatures were tested in order to analyze and compare ENSO, and PDO related variability. A two-tailed standardized test statistic ( $z^{*}$ ) was the technique used for the comparison of the sample means. Means for the total time series studied served as the expected frequencies of occurrence. All statistical tests assumed the null hypothesis, or that no a priori relationship was present among the variables tested. Confidence levels of 90\%, 95\%, and 99\% were all tested.

\subsection{Location}

The previous study [2] chose Jefferson City, Missouri as the principal site for data collection, and used this as the representative site of the entire East-Central Missouri Ozarks (Figure 1). Utilizing principal component analysis from [32]-[34], and [2] showed that focusing on Jefferson City is sufficient to make conclusions about interannual variability in the East-Central Missouri Ozarks region as a whole. Thus following those works, this study uses Jefferson City as the representative data site, but for a slightly different region. Here we use the NWS climate divisions including the Northwest Prairie, Northeast Prairie, West Central Plains, West Ozarks, East Ozarks and the Bootheel (Figure 2), a similar region to [2]. Additionally, it was originally recognized that these divisions were categorized into subgroups that possessed similar climatological and geographical characteristics (Climatological Data: Missouri, 2013. http://www.ncdc.noaa.gov). This study includes the Northeast Prairie, the Eastern Ozarks, and the part of the West Central Plains. Lastly, the Jefferson City reporting site moved three times during the study period. Nonetheless, every Jefferson City site is less than one degree of longitude and latitude from another. The Jefferson City Water Plant is the station current location and the location with the most longevity, encompassing the bulk of data used here. As in [12] there is no systematic impact from these moves.

\subsection{ENSO and PDO}

El Niño Southern Oscillation (ENSO) and Pacific Decadal Oscillation (PDO) are the two main teleconnections considered for this research [12], as these have the strongest correlation with regional weather [35]. Other teleconnections such as the North Atlantic Oscillation and Arctic Oscillation did not correlate as strongly. The Japan Meteorological Agency (JMA) ENSO index is available through the Center for Ocean and Atmospheric Prediction Studies (COAPS) from 1868 to present (JMA sea surface temperature (SST) ENSO Index 


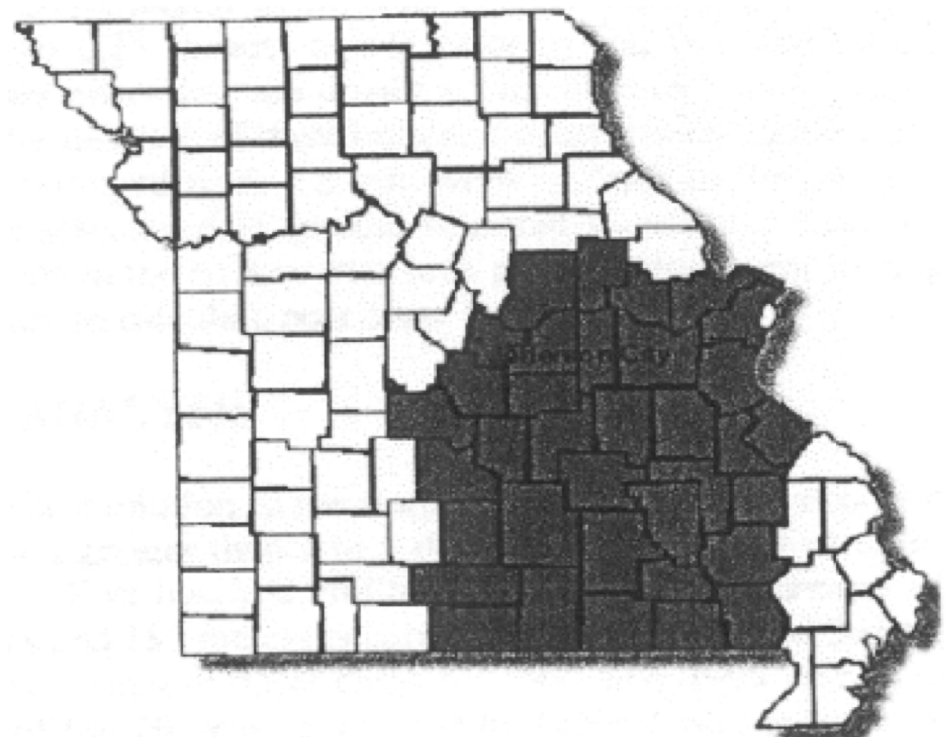

Figure 1. From Ratley et al. (2002), the location of the study region including Jefferson City, Missouri. This area is bounded by the edge of the East Ozarks to the west, the Mississippi River to the east, the Missouri River to the north and the Missouri/Arkansas border to the south.

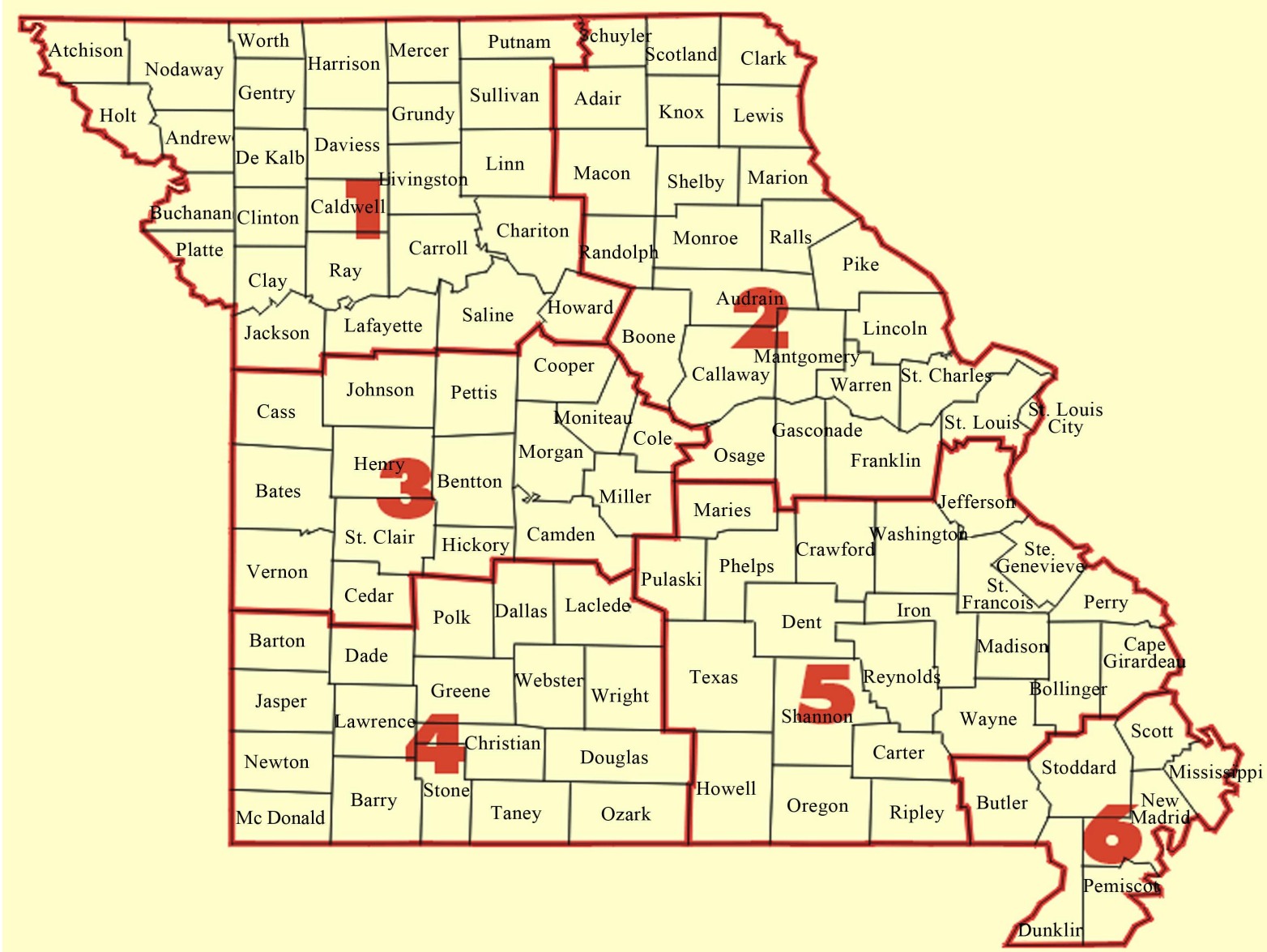

Figure 2. United States Department of Commerce Weather Bureau’s Climatological Data: Missouri Section, Divisions, 1957 to Present, image courtesy of the Climate Prediction Center (CPC). 
http://www.coaps.fsu.edu/jma). The JMA SST ENSO Index has been widely used in other published works (e.g., [23], [36], and [37] are some recent examples), and is also used here (Table 1). Also, [38] found that, however, while the JMA index is more sensitive to La Niña events than other definitions, it is less sensitive than other indices to El Niño events. The JMA classifies ENSO phases using SST within the bounded region of $4^{\circ} \mathrm{S}$ to $4^{\circ} \mathrm{N}$, $150^{\circ} \mathrm{W}$ to $90^{\circ} \mathrm{W}$. The JMA defines the inception of an ENSO year as 1 October, and its conclusion on 30 September of the next year.

The Pacific Decadal Oscillation (PDO) positive and negative modes are catalogued also by the Center for Ocean-Atmospheric Prediction Studies (COAPS). The most important effect of PDO is how it interacts with ENSO during certain phases to create an enhanced effect on temperatures and precipitation variability (e.g., [23] [26]). The characteristics of these modes are less pronounced than those for ENSO due to the fifty- to seventy-year cycle of PDO (e.g., [39] [40]). COAPS describes the PDO phases (Table 2) as follows: the High (+) PDO phase is characterized by cold SSTs in the north central and western Pacific Ocean, warm SSTs off the western coast of North America, and a deep Aleutian low, while the Low $(-)$ phase of the PDO is characterized by warm SSTs in the north central and western Pacific Ocean, cool SSTs off the western coast of North America, and no pronounced Aleutian low. The start date of the current PDO cycle from COAPS agrees with the independent analysis of [7], based on the same SST patterns.

Table 1. Center for Ocean-Atmospheric Prediction Studies Japan Meteorological Agency El Niño Southern Oscillation Index, 1948 to present. Modes are El Niño (EL), La Niña (LA) and Neutral (NEU).

\begin{tabular}{lccccc}
\hline Year & Classification & Year & Classification & Year & Classification \\
\hline 1948 & NEU & 1970 & LA & 1992 & NEU \\
1949 & LA & 1971 & LA & 1993 & NEU \\
1950 & NEU & 1972 & EL & 1994 & NEU \\
1951 & EL & 1973 & LA & 1995 & NEU \\
1952 & NEU & 1974 & LA & 1996 & NEU \\
1953 & NEU & 1975 & LA & 1997 & EL \\
1954 & LA & 1976 & EL & 1998 & LA \\
1955 & LA & 1977 & NEU & 1999 & LA \\
1956 & LA & 1978 & NEU & 2000 & NEU \\
1957 & EL & 1979 & NEU & 2001 & NEU \\
1958 & NEU & 1980 & NEU & 2002 & EL \\
1959 & NEU & 1981 & NEU & 2003 & NEU \\
1960 & NEU & 1982 & EL & 2004 & NEU \\
1961 & NEU & 1983 & NEU & 2005 & NEU \\
1962 & NEU & 1984 & NEU & 2006 & EL \\
1963 & EL & 1985 & NEU & 2007 & LA \\
1964 & LA & 1986 & EL & 2008 & NEU \\
1965 & EL & 1987 & EL & 2009 & EL \\
1966 & NEU & 1988 & LA & 2010 & LA \\
1967 & LA & $\mathbf{1 9 8 9}$ & NEU & 2011 & NEU \\
1968 & NEU & 1990 & NEU & 2012 & NEU \\
1969 & EL & 1991 & EL & 2013 & NEU \\
\hline & & & & & \\
\hline
\end{tabular}


Table 2. Center for Ocean-Atmospheric Prediction Studies Pacific Decadal Oscillation Index, 1910 to present. Modes are high (positive) and low (negative).

\begin{tabular}{cc}
\hline Year Range & Mode \\
\hline $1910-1924$ & - PDO \\
$1925-1946$ & + PDO \\
$1947-1976$ & - PDO \\
$1977-1998$ & + PDO \\
$1999-2014$ & $-P D O$ \\
\hline
\end{tabular}

\subsection{Ratley et al. 2002 Temperature Criterion}

We used the criterion of [2], which is set in order to filter out synoptic-scale perturbations. The thresholds for surface temperatures were set at fifteen days. The criterion used by [2] for identifying the spring to summer transition date using $500 \mathrm{hPa}$ heights was the start date for the first period of at least 10 consecutive days where the heights are in excess of $5820 \mathrm{~m}$ over the entire study region. The $5820 \mathrm{~m}$ contour is frequently used as an indicator of the difference between the baroclinicity of the mid-latitudes and the quasi-barotropic nature of the subtropics [2]. This height minimum is typically the trailing equatorward edge of tightly-packed mid-latitude height gradients, as also demonstrated in a derecho study by [41], and in study of summer perturbations by [42]. Additionally, since the 5820 height contour is at the equatorward edge of the $500 \mathrm{hPa}$ height gradients, they frequently coincide with gradients of potential temperatures near $350 \mathrm{~K}$ on the 2.0 Potential Vorticity Unit (PVU) (e.g, [43]) in identifying the general location of the jet stream. Potential vorticity is conserved on surfaces of potential temperature, but the above argument is not strictly true as potential temperature or potential vorticity will not be strictly conserved on a height surface (e.g., [44]). Nonetheless, many papers have demonstrated the general utility of potential vorticity quantities in defining features in the jetstream. Thus we are confident that this choice of contour has dynamic relevance to the study here.

The temperature criteria for a summer start date are as follows from [2], and using a 15-day window for surface based data is sufficient for removing smaller-scale impacts [45]:

1) The first date of a fifteen-day consecutive period where the mean temperature exceeds $70.0^{\circ} \mathrm{F}\left(21.1^{\circ} \mathrm{C}\right)$, and at least ten of those fifteen days have a temperature at, or exceeding, $75.0^{\circ} \mathrm{F}\left(23.9^{\circ} \mathrm{C}\right)$.

2) The first date of a fifteen-day consecutive period where the maximum temperature exceeds $77.0^{\circ} \mathrm{F}\left(25.0^{\circ} \mathrm{C}\right)$ and at least ten of those fifteen days have a temperature at, or exceeding, $82^{\circ} \mathrm{F}\left(27.8^{\circ} \mathrm{C}\right)$.

Temperatures are reported in the National Climatic Data Center in degrees Fahrenheit, and then converted to Celsius.

\subsection{Blocking Criterion and Integrated Regional Enstrophy (IRE)}

In order to identify blocking events, we used the criterion defined in [28] and references therein. In this work, the characteristics of blocking upstream in the Pacific Region $\left(140^{\circ} \mathrm{E}-100^{\circ} \mathrm{W}\right)$ are examined in order to determine what role the occurrence of blocking might play in the configuration of the jet stream over the region, in a manner similar to [28]. Here we examine spring and summer blocking (as in [28]) in order to determine if the spring season provides precursory indication of the summer season's activity and thus the seasonal conditions in the study region. All the events used for this study can be found at the University of Missouri's blocking archive (http://weather.missouri.edu/gcc). Blocking events are available from 1969-2014. Studies going back to the early 1980's (e.g., [46] [47]) show the relevance of the conditions upstream, including the flow regime to the conditions in the area of interest. The character of the Pacific Region flow and blocking correlates strongly to weather conditions in the study region (e.g., [35]).

The study of [1] used the wave amplitude index to quantify the kinetic energy in the northern hemisphere large-scale flow regime. Also, [2] demonstrated that the spring-to-summer transition was associated with a decrease in the wave-amplitude index. Here we used the integrated regional entrophy (IRE) to represent the largescale flow regime. The study of [38] proposed that the stability of the Northern Hemisphere flow was approximately equal to the enstropy integrated over the Northern Hemisphere in a barotropic and frictionless flow. Then [6] (and references therein) demonstrated the utility of the integrated regional estrophy (IRE) diagnostic 
(based on [48]) to study the relationship of flow regime stability to the onset and decay of blocking. In a geostrophic flow velocity and vorticity are related to the gradient and laplacian of the height field, respectively. For the purpose of this discussion, then kinetic energy and enstrophy are the square of these quantities, and these quantities should be smaller overall when the weaker, more zonal Northern Hemisphere summer season flow regime [49] becomes established.

\section{Climatological Analysis}

\subsection{Spring to Summer Transitions in the Study Region}

The results of this study produced a transition date using each criterion, where data was available, and a final spring-to-summer transition date based on these three criterions for the 68 year period (1948-2015). There were a few years before 1980 in which Jefferson City temperature data were absent, including 1967. The $500 \mathrm{hPa}$ height criterion provided a date for every year except 1967. In order to provide a possible date for that year, Columbia Regional airport data were used to provide continuity for some of the analyses, and the date identified was June 3 and 4 for each temperature criterion. It was also noted that the $500 \mathrm{hPa}$ height criterion beginning with June 4 was only met for seven consecutive days, and at nine of the ten day period (only one time did not). During the summer as a whole, the longest consecutive period for meeting the criterion was eight days. Thus, a transition date of 4 June for 1967 seems quite plausible based on data used for this analysis.

An examination of Table 3 shows that the mean spring and summer temperatures and their standard deviations for the entire period, and these are close to the current 30 year means and standard deviations. The trend for summer temperatures would display a cooling trend using linear regression, but this trend was not statistically significant, a result identical to those of [13]. The spring season, however, Figure 3(a) showed a significant warming (at the $90 \%$ confidence level), and this resulted in a statistically significant decrease in the spring to summer temperature difference (at the $90 \%$ ). This result is consistent with observations from other parts of the earth, and is consistent with the prevailing idea that, in a warmer world, the cold season will warm at a faster rate [50].

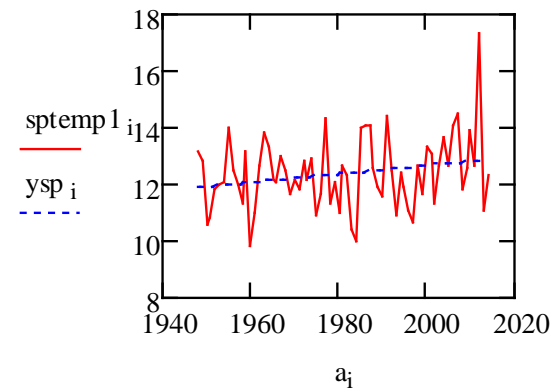

(a)

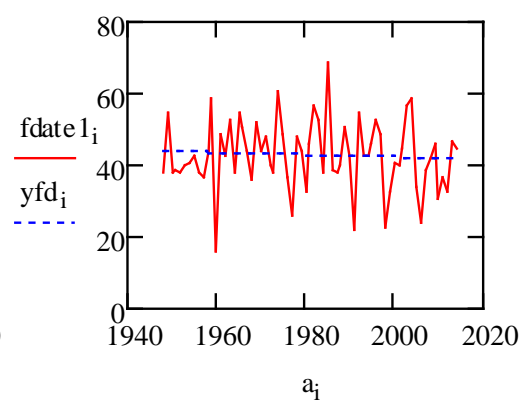

(b)

Figure 3. (a) Mean spring season temperature $\left({ }^{\circ} \mathrm{C}\right.$ ) versus time (years) and (b) the final date determined (days from 1 May) for each year. The blue dotted line is the linear regression line.

Table 3. Statistics for the three criterion used to identify the spring-summer transition date, and temperature data for the spring and summer seasons and their differences from 1948-2014.

\begin{tabular}{ccc}
\hline Variable & Mean & Standard deviation \\
\hline 500 hPa criterion (days) & 51-June 20 & 13.4 \\
Mean temperature criterion (days) & 42-June 11 & 9.2 \\
Maximum temperature criterion (days) & 38-June 7 & 14.1 \\
Final date (days) & 43-June 12 & 9.7 \\
Summer temperature $\left({ }^{\circ} \mathrm{C}\right)$ & 24.3 & 1.1 \\
Spring temperature $\left({ }^{\circ} \mathrm{C}\right)$ & 12.4 & 0.3 \\
Difference $\left({ }^{\circ} \mathrm{C}\right)$ & 11.9 & 0.4 \\
\hline
\end{tabular}


The average transition date for the entire data set, 1948-2015, is 12 June, not including 1967 . The median transition date is also 12 June, and the median values for all variables in Table 3 were the same when the means were rounded. June was, by far, the most common month for final transition dates, accounting for $85.3 \%$ of all chosen values, and $78.0 \%$ of all transitions occurred within one standard deviation of the mean. Eight transitions occurred in May. These characteristics imply that the data set is close to a normal distribution, but one that is more peaked (kurtosis). Since the 1967 transition date was identified as 3 June, including it in the analysis does not change the overall statistics.

Concurrent with the decreased temperature differences between spring and summer, the trend for the final summer onset day is indicated to be occurring earlier (Figure 3), a trend that was significant at the 99\% level for the $500 \mathrm{hPa}$ data, and the mean temperature criterion data. The trend for the decreased temperature difference was significant at the at the $90 \%$ confidence level. Only the maximum criterion trended toward a later date, and this was significant at the $95 \%$ confidence level. These contradictory trends are possible since the summer minima trended higher, but also the dew point trend was significantly higher [13]. A higher dew point correlates with higher minima, and this is also consistent with the prevailing character of a warming climate [50].

A further examination of the individual criterion demonstrates that the daily mean temperature and the final date chosen were similar statistically (Table 3) and the correlation between the two time series was 0.73 , a value significant at the $99 \%$. This was by far the strongest association in this data when cross correlating each time series. The $500 \mathrm{hPa}$ and maximum temperature criterion were similar in their variation (standard deviation was 14 days), but the maximum temperature produced the earliest onset date and the $500 \mathrm{hPa}$ the latest. While the 500 $\mathrm{hPa}$ criterion correlated with the final date at the 95\% confidence level (0.28), the maximum criterion did not correlate with any other criterion at a statistically significant level. The $500 \mathrm{hPa}$ height, the mean temperature criterion, and the final date chosen correlated positively with the summer mean temperature as might be expected, and these correlations were significant at the 99\%, 90\%, and 99\% confidence level, respectively. There was only one other statistically significant relationship between these criterion and temperatures, and that was between the mean temperature criterion and the spring mean temperatures.

At the beginning of this work, it was proposed that the 500-mb height data would be the most useful criterion, as upper-air analyses are not subjected to surface observation errors and influences. However, there are errors inherent in the 500-mb data as well, and the years before the satellite era may possess larger error (e.g., [51]). Based on the statistical analysis above, an argument could be made that the mean temperature criterion would be the most useful for identifying the spring-summer transition date in the study region.

A comparison of this work and [2] (Table 4) shows a similar pattern to the statistics for the larger data set in that the $500 \mathrm{hPa}$ criterion produced the latest date while the maximum temperature date was the earliest. Also, the mean temperature criterion and final date were within one day of each other in both studies. The study of [2] found that for 12 of the years (60\%) of their 1981-2000 dataset, all three summer onset dates fell within a 10-day moving window. In the longer data set here, only 20 years (33\%) were characterized in the same manner. In order to determine why this difference was so large we sampled the same 20 years as in [2] using our criterion. Here we found 11 years (55\%) fit the same criterion, or a difference of only one year.

An examination of the two studies shows that a slightly different methodology was used to determine the onset date. The rules employed by [2] specified that the final date chosen must match one of the other criteria, which is more arbitrary. Here, we used similar rules except that the final date was the average date provided by the available criterion for that year, and thus, did not have to match any of the three criteria. The average of the two analyses gave final dates that were an average of 4 days apart. In this study of the period of [2], five transition days (25\%) fell within twenty-four hours of all criterion. Thirteen transition days (65\%) fell within five days of one another, still within the time frame of the synoptic period. Seventeen days (85\%) were within ten

Table 4. As in Table 3 except for relevant values from Ratley et al. (2002).

\begin{tabular}{ccc}
\hline Variable & Mean & Standard deviation \\
\hline 500 hPa criterion (days) & 48-June 17 & 12.0 \\
Mean temperature criterion (days) & 47 -June 16 & 13.0 \\
Maximum temperature criterion (days) & $42-J u n e ~ 11$ & 12.0 \\
Final date (days) & 43-June 15 & 10 \\
\hline
\end{tabular}


days, or planetary-scale time frame. The outcomes here chose an earlier transition date $45 \%$ of the time, and a later onset date $50 \%$ of the time, thus overall the change in assigning the final date did not result in large difference between the two studies.

\subsection{Pacific Region Blocking}

There has been speculation that frequency of Northern Hemisphere blocking has increased during the last two decades. Comparing our results to those of [52] (see Table 5 and Figure 4), indicate there has been a very sharp increases in the frequency and number of blocking events and blocking days in the Pacific region $\left(140^{\circ} \mathrm{E}-\right.$ $100^{\circ} \mathrm{W}$ ) spring (significant at the $99 \%$ confidence level) and summer (significant at the $95 \%$ confidence level) seasons when the study is extended to the current time. There was, however, no significant change in the intensity of blocking in this region. The study of [52] covered the period 1970-2000, thus the sharp increase in blocking has occurred since this time. Also, [11] associated more and stronger Pacific Region summer blocking to cooler, and wetter summers in the region. Here we find a strong correlation between the occurrence of spring and summer blocking and regional summer temperatures (more blocking, cooler conditions for the study region), but not significant at the $90 \%$ and $95 \%$ confidence level as in [35]. This is especially true if only blocking east of dateline is included.

This and many other studies, even those going back to the 1980s (e.g., [53] [54]) show that the occurrence of Pacific Region blocking, especially in the East Pacific is associated with cooler winter temperatures in the region. This same correlation appears to be true for the summer season as well [11]. The occurrence of blocking, however, did not correlate with any of the onset criterion here for the final day chosen. This may be expected since the occurrence of blocking is quasi-random. However, the association of blocking with the character of seasonal temperature and precipitation characteristics is well-documented. Thus, it would seem that the influence of blocking may be more indirect and this issue will be explored versus interannual variations.

\subsection{Synoptic Climatology and Dynamic Analysis}

In order to examine the effectiveness of this criterion in identifying a date for the spring-summer transition, the $850 \mathrm{hPa}$ and $500 \mathrm{hPa}$ heights were used to examine the lower (Figure 5) and mid-tropospheric (Figure 6) air flow for the 30 day period before and after the nominal transition date in order to identify whether a difference existed. Five particular years were chosen in order to represent an early onset (2 June 2012) a late onset (28 June

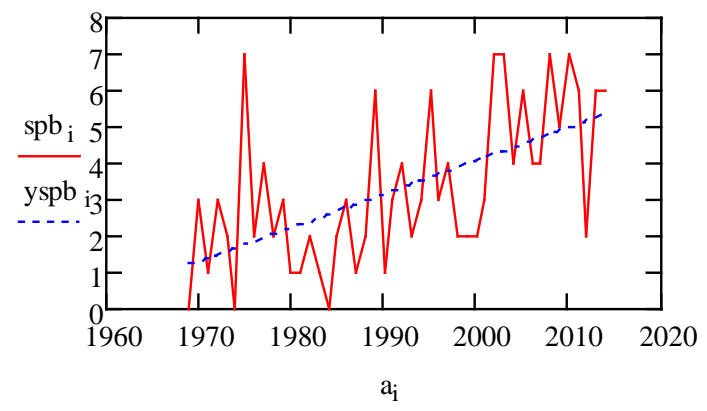

(a)

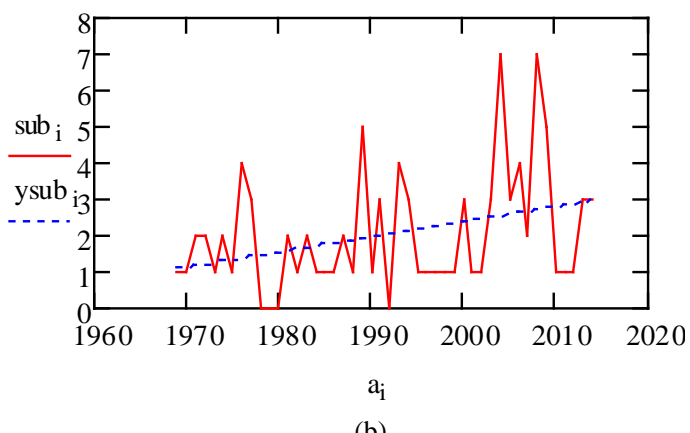

(b)

Figure 4. The frequency of (a) spring (FMAM) and (b) summer (JJA) blocking in the Pacific Region. The blue dotted line is a linear regression model.

Table 5. The mean spring and summer Pacific Region blocking $\left(140^{\circ} \mathrm{E}\right.$ to $\left.100^{\circ} \mathrm{W}\right)$ from $1969-2015$ as compared to Wiedenmann et al. (2002). The comparison with the earlier work is shown as a departure (current-Weidenmann et al., 2002).

\begin{tabular}{cccc}
\hline & Number/Duration & Total days & Intensity \\
\hline Spring & $3.3 / 8.8(+1.4 /+1.6)$ & $29.2(+15.6)$ & $3.33(+0.73)$ \\
Summer & $2.0 / 8.7(+0.7 /+1.7)$ & $17.4(+8.6)$ & $2.15(+0.04)$ \\
\hline
\end{tabular}




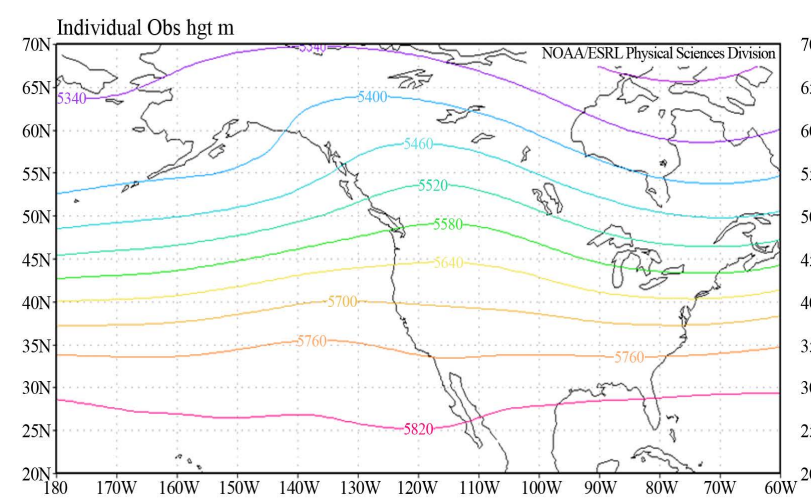

(a)

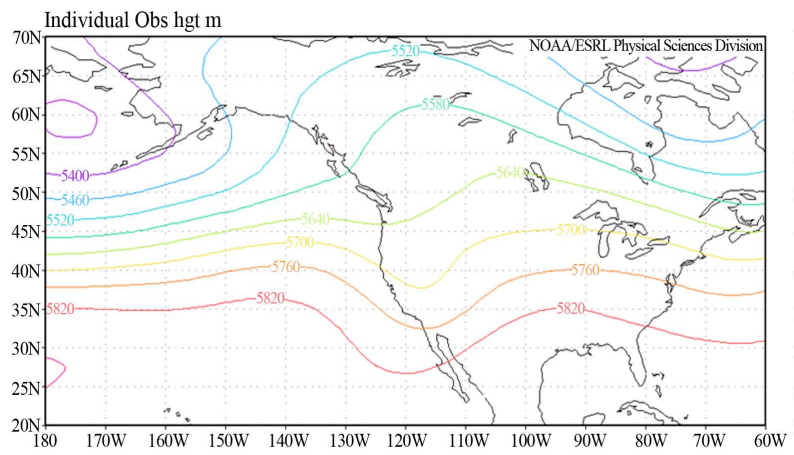

(c)

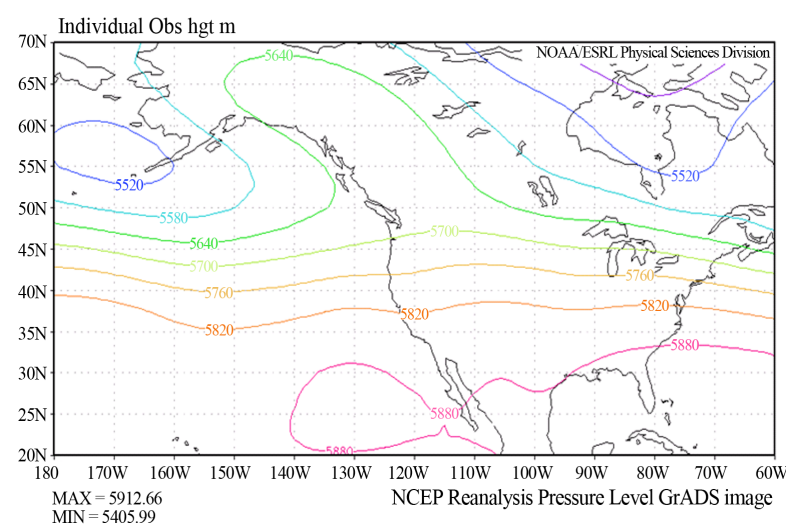

(e)

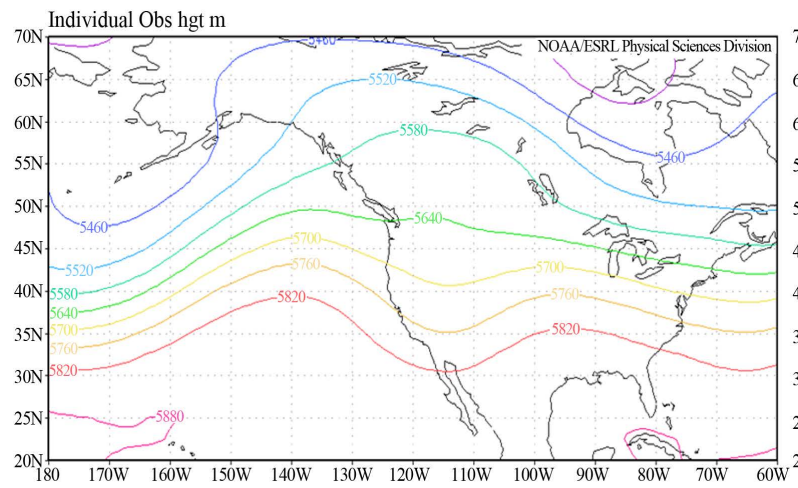

(g)

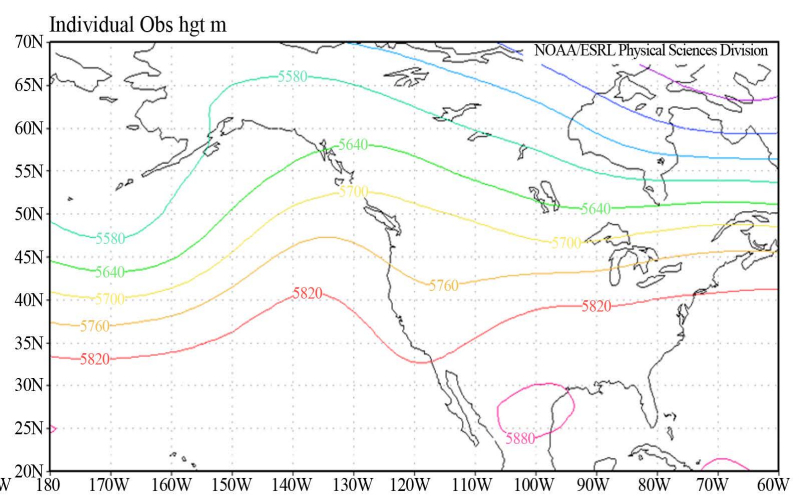

(b)

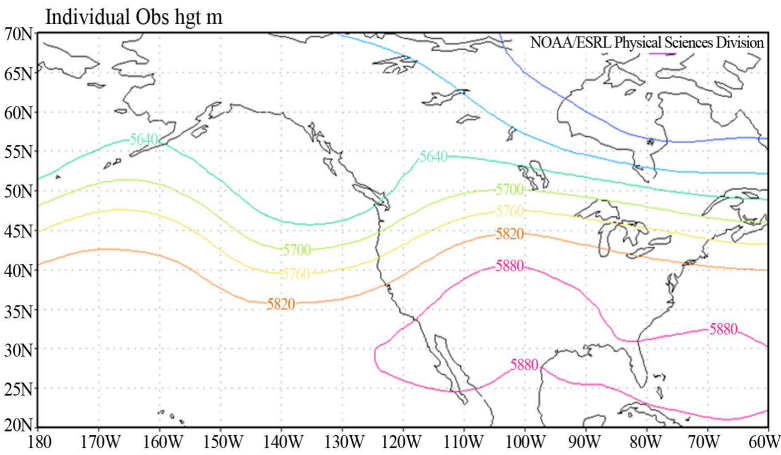

(d)

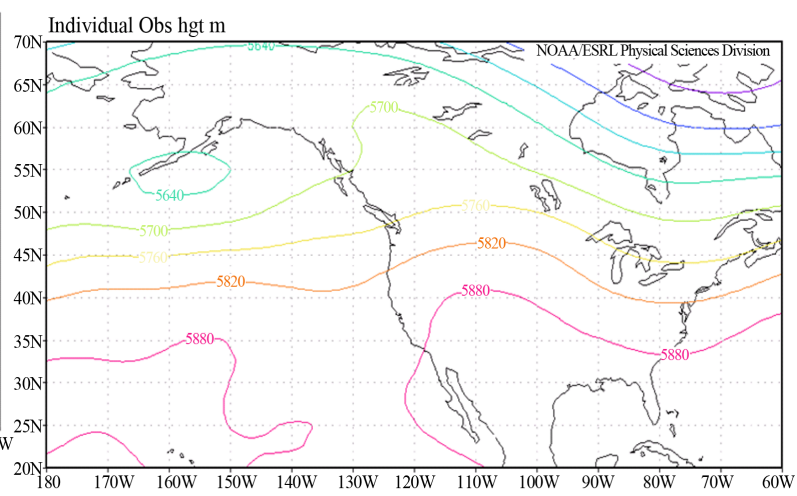

(f)

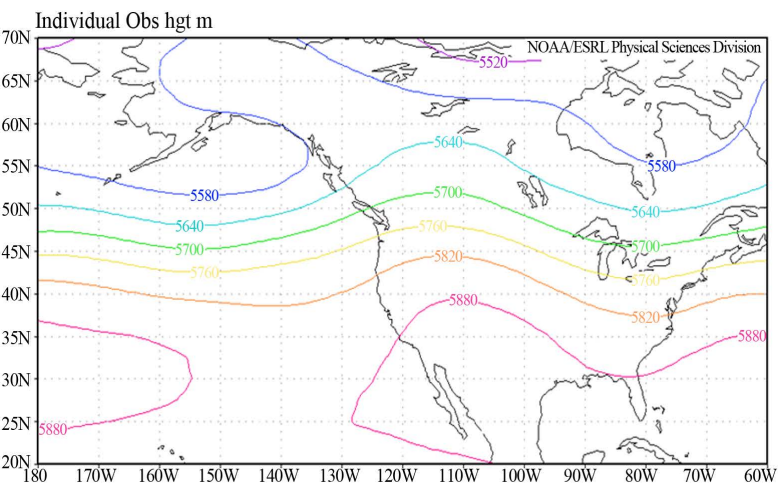

(h) 


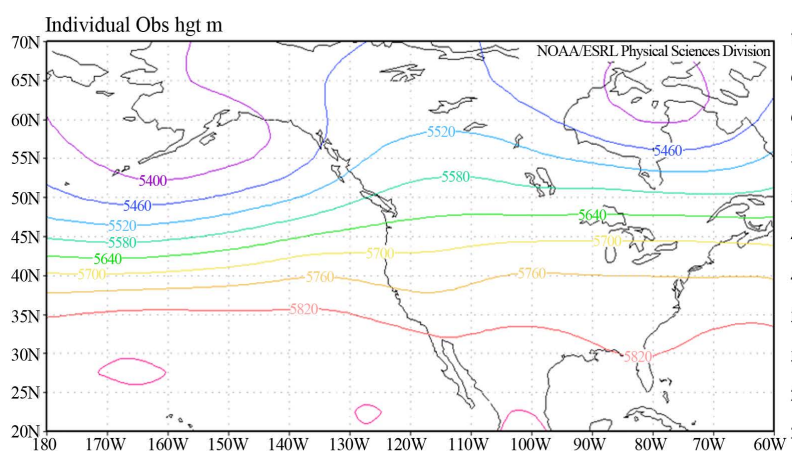

(i)

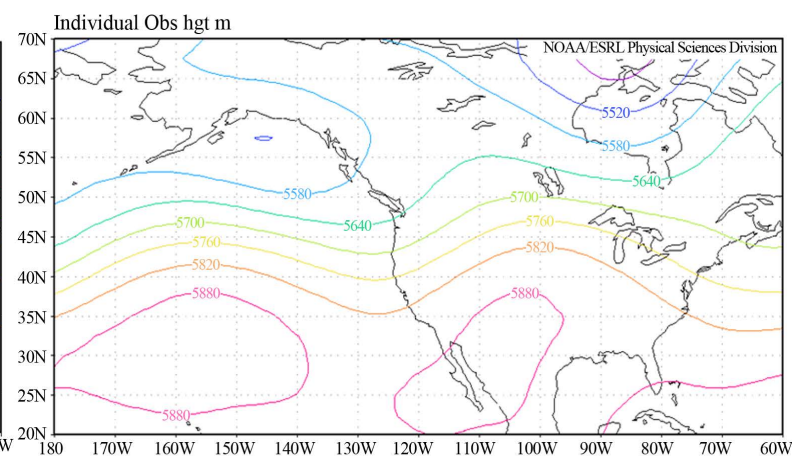

(j)

Figure 5. The mean 1200 UTC 500 hPa height map for the East Pacific and North America for the (a), (c), (e), (g), (i) 30 day period prior to, and (b), (d), (f), (h), (j) 30 day period following the identified onset date found in this study. The years used are (a), (b) 1967, (c), (d) 1971, (e), (f) 2004, (g), (h) 2008, and (i), (j) 2012. The identified dates for transition were, 4 June, 17 June, 28 June, 11 June, and 2 June, respectively. The contour interval is every 6 dam.

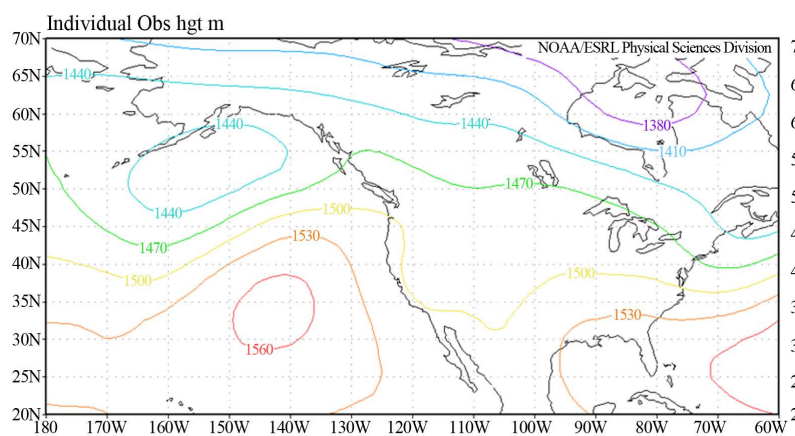

(a)

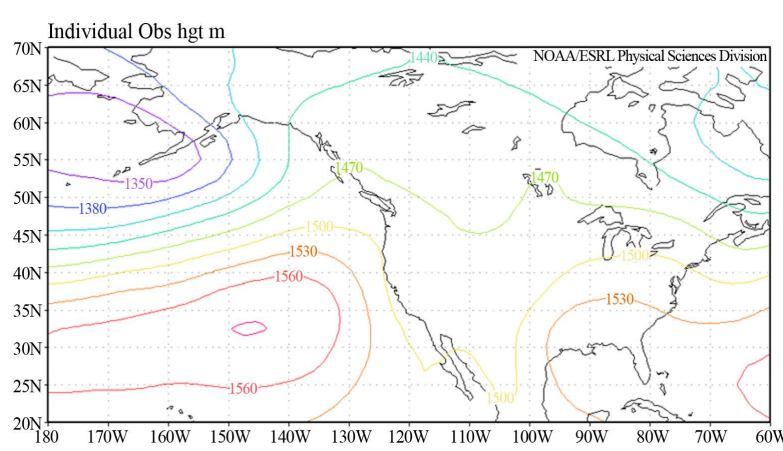

(c)

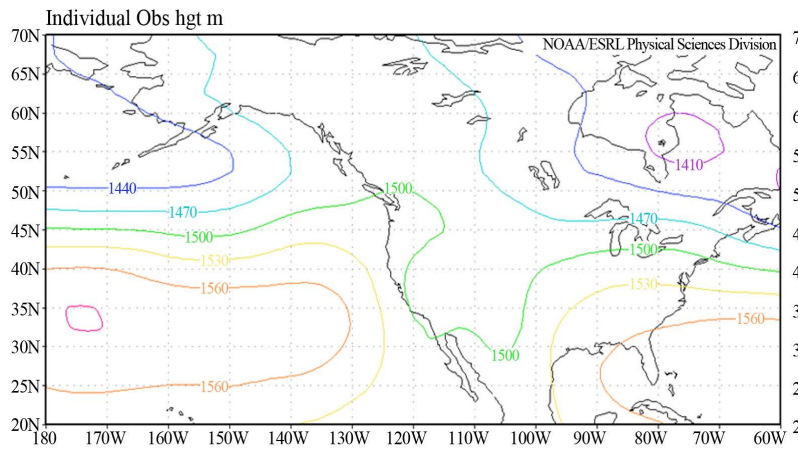

(e)

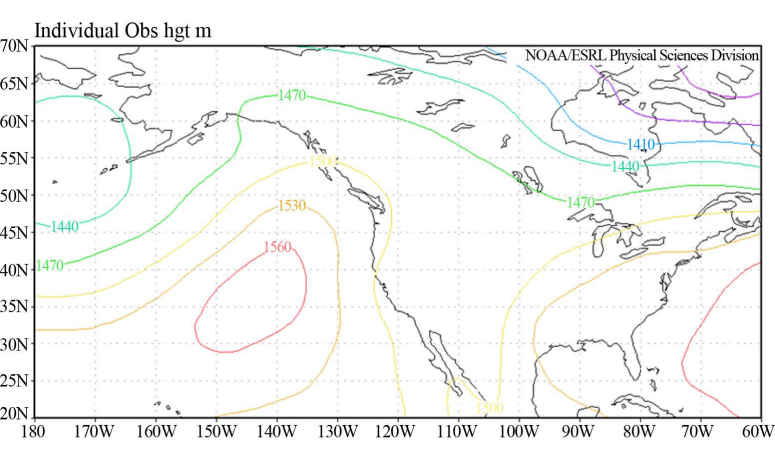

(b)

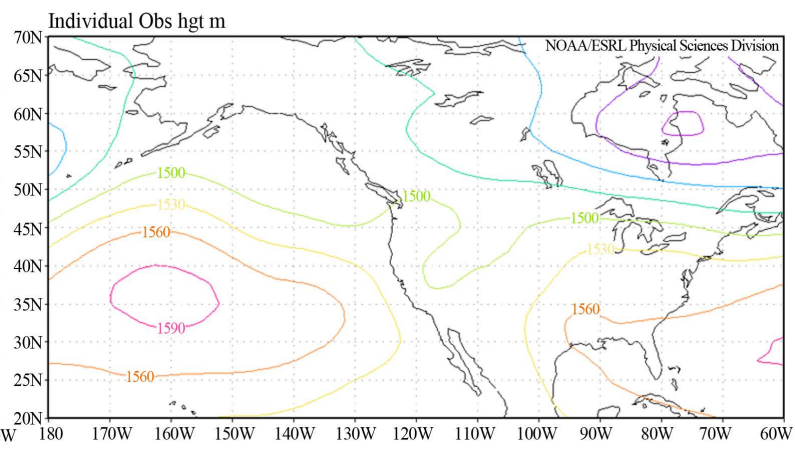

(d)

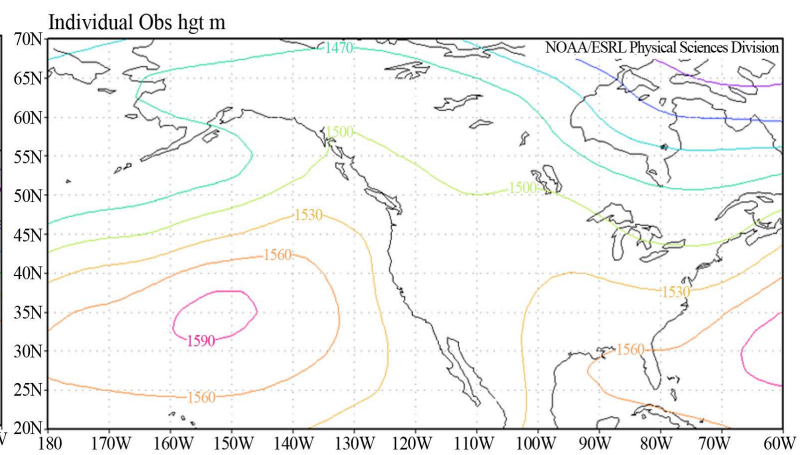

(f) 


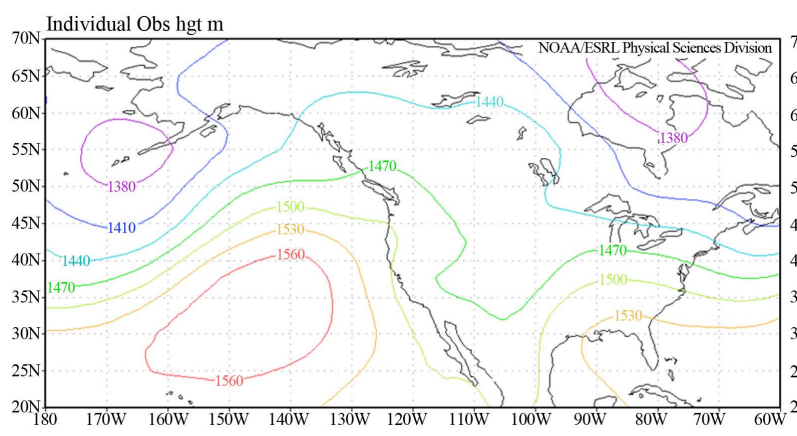

(g)

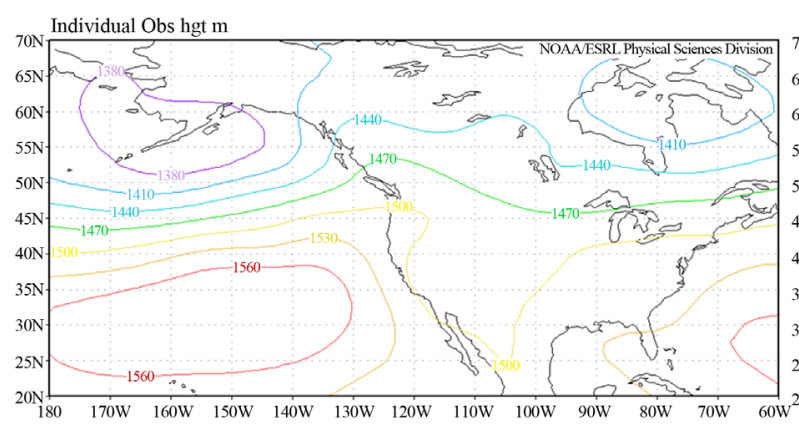

(i)

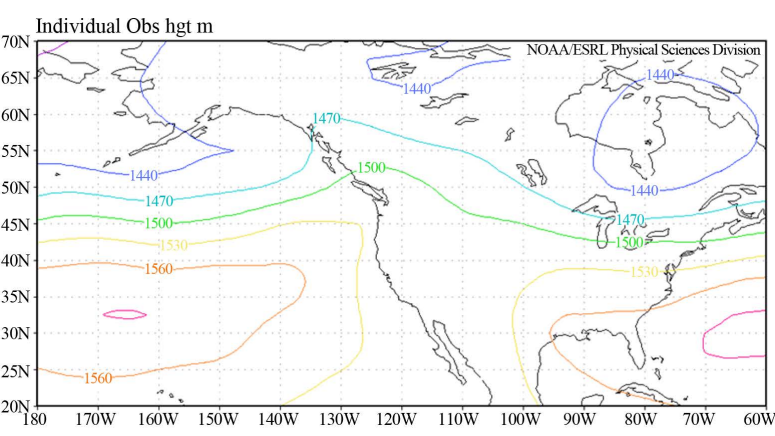

(h)

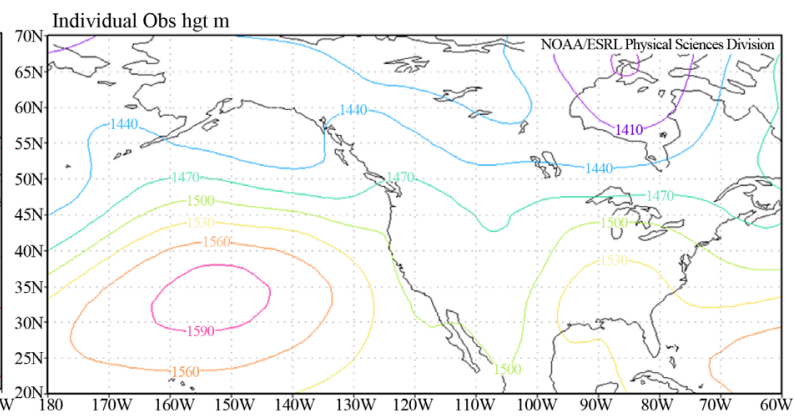

(j)

Figure 6. As in Figure 5, except at the $850 \mathrm{hPa}$ level and a contour interval of 30 dam.

2004), one close to the mean (11 June 2008), and two of particular interest (4 June, 1967-the date inferred above in section 3a for the year that lacked a criterion, and 17 June, 1971-Midwestern drought). Table 6 shows the summer mean temperature and total precipitation and their relative anomalies for each year relative to the 1981-2010 anomalies.

In all five cases at $500 \mathrm{hPa}$ (Figure 5), the $5820 \mathrm{~m}$ contour was located within or equator ward of the study region in the 30 day period before the transition date. There was either split flow or ridging over the Rockies as is typical of the colder season. In the 2012 case, the flow was more zonal and the jet stream was clearly north of the region (but not the $582 \mathrm{~m}$ contour). In the 30 day period following the onset date, the $5820 \mathrm{~m}$ line and the jet stream was clearly poleward of the region, and summer season ridging was established in North America. Note that during the prior period for the year 2004 there was blocking in the Alaska Region. Similar to the case for the hot dry summer of 2012, it was noted that the years 1980 and 1954 also had earlier onset dates and a similar difference between the pre- and post-transition date (not shown). Thus, this criterion is rather effective for intensifying this change in the character of the $500 \mathrm{hPa}$ flow over the region.

At the $850 \mathrm{hPa}$ level (Figure 6), the post-onset dates for 1967, 1971, and 2012 show that the 850 hPa flow over the study region was more meridional and the stronger flow was to the west over Texas and Mexico, while the 2004 and 2008 flow regimes were more zonal and originally out of the gulf of Mexico. Table 6 shows that the former three years were dry over the study region, two of them extremely dry. This result for dry years is consistent with the study of [13] who looked at summer season dew points in the region. The latter two years were wetter than normal. During the pre-onset date period, the flow was more zonal over the study region for all the years except for the year 2012. Like the $500 \mathrm{hPa}$ analysis, however, these were all different from the postonset flow region.

Here we demonstrate using the integrated regional enstrophy (IRE) that the stability of the northern hemisphere flow (IRE) increases (decreases) in association with the time period identified for the spring-to-summer transition date. Figure 7 shows a time series of the IRE quantity from 1 May to 31 July for both 1971 and 2008. The transition date in 1971 was identified as 17 June. The IRE diagnostic for that year (Figure 7(a)) was higher for the period before 17 June, and considerably less following this date. However, the transition during May and June was more gradual. In the case of 2008, the transition date chosen was 11 June, and the IRE diagnostic increases rapidly (possibly indicating instability and flow regime transformation-[6]), and then decreases to a 
Table 6. The mean temperatures $\left({ }^{\circ} \mathrm{C}\right)$ and total precipitation $(\mathrm{mm})$ and their anomalies for the years 1967, 1971, 2004, 2008, and 2012. The * represents years that were greater than one standard deviation from the normal $\left(1.2^{\circ} \mathrm{C}\right.$ and $\left.13.1 \mathrm{~mm}\right)$.

\begin{tabular}{|ccc|}
\hline Year & Temperature & Precipitation \\
\hline $\mathbf{1 9 6 7}$ & 23.0 & 20.0 \\
$\mathbf{1 9 7 1}$ & 24.2 & $18.2^{*}$ \\
$\mathbf{2 0 0 4}$ & $21.9^{*}$ & 35.8 \\
$\mathbf{2 0 0 8}$ & 23.7 & $47.1^{*}$ \\
$\mathbf{2 0 1 2}$ & $26.8^{*}$ & $14.5^{*}$ \\
\hline
\end{tabular}

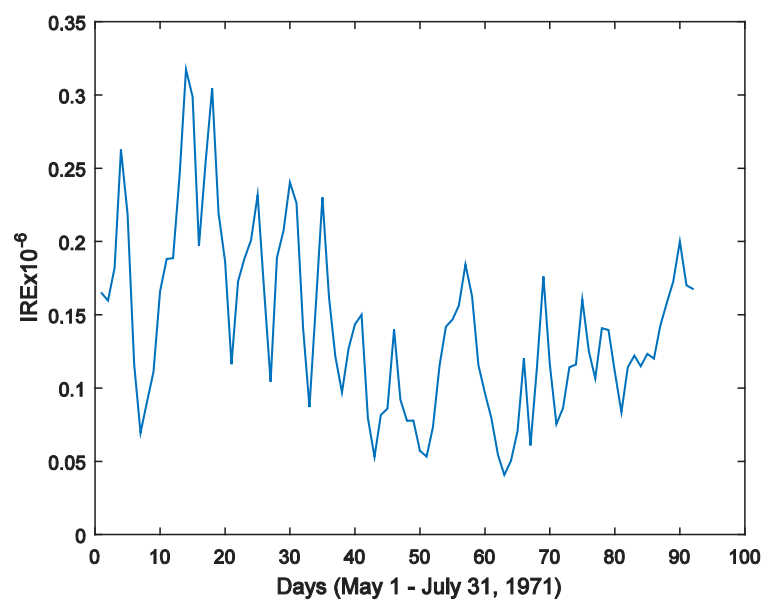

(a)

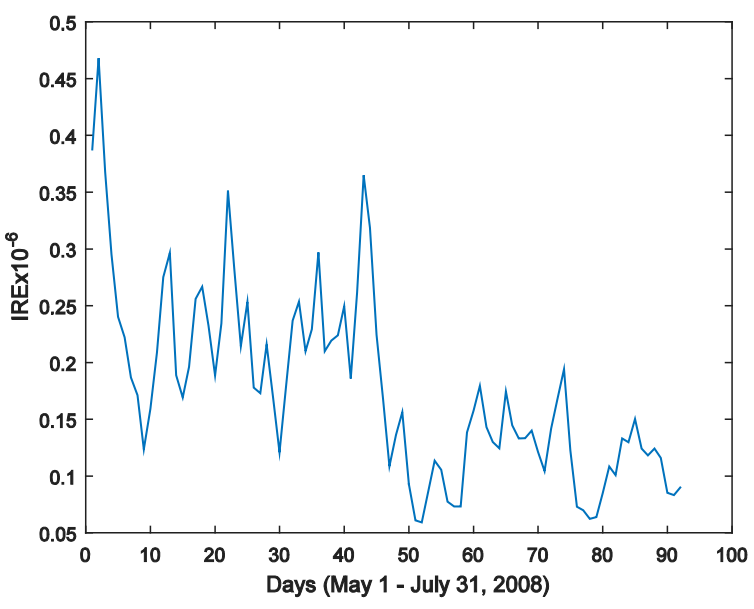

(b)

Figure 7. The Integrated Regional Enstrophy Diagnostic (IRE) for the time period 1 May to 31 July (in days from 1 May) for (a) 1971, and (b) 2008.

much lower level for the rest of the series. These examples demonstrate that the IRE diagnostic does indicate that the flow regime changes occur in the time frame identified by the criterion used here. Additionally, the IRE indicates that the summer season flow is more stable, and thus weather prediction is more favorable as shown statistically for the summer season in region [55].

\section{Interannual and Interdecadal Variability}

In order to identify the interannual and interdecadal variability a periodogram of the summer temperatures, the final date chosen, and Pacific Region blocking were constructed using the method of cycles (e.g., [12]) (Figure 8). All of these show statistically significant interannual variability, but there is little indication of interdecadal variability, as was found for regional precipitation events (e.g., [56] [57]), except for the blocking time series which shows significant variability beyond ten years. The interannual variability in Figure 8(a) for example can be inferred from the diagram which shows a significant peak at wave number 18, which in the 68 year data set represents variability with a period of three to four years. Interdecadal variability in the blocking occurrences (Figure 8(c)) is evidenced with a peak at wave number three and ten (46 years total) or at 15 and 5 years, respectively. Table 7 shows the number of early versus late onsets for each mode of ENSO and the PDO confirming that there is no strong interdecadal signal in the spring-to-summer onset. As may be expected for neutral years, there is no discernable tendency toward late or early onsets, and the same outcome can be inferred for years after El Niño onset, which [2] also found. However, for years after La Niña onsets, there is a stronger tendency for early onsets, especially during -PDO. Both La Niña years in Table 6 were early onsets. Additionally, [2] studied a period that contained few La Niña onsets, thus there is no basis for comparison with this study.

Table 8 shows the occurrence and of blocking within the Pacific region for each year shown in Figure 5, Figure 6. In section 3 we found a correlation between the more frequent occurrence of blocking and cooler, 
Table 7. The number of early or late onset dates for summer stratified by ENSO phase for $+\mathrm{PDO} /-\mathrm{PDO}$.

\begin{tabular}{cccc}
\hline ENSO phase & Early onset & Late onset & On average date \\
\hline El Nino (15) & $3 / 4$ & $2 / 6$ & $0 / 0$ \\
Neutral (36) & $4 / 9$ & $8 / 11$ & $3 / 1$ \\
La Nina (16) & $0 / 10$ & $1 / 4$ & $0 / 1$ \\
\hline
\end{tabular}

Table 8. As in Table 5, except for the years in Figure 5, Figure 6 where blocking was examined.

\begin{tabular}{cccc}
\hline & Number/Duration & Total days & Intensity \\
\hline Spring 1971 & $1 / 14.0$ & 14 & 2.25 \\
$\mathbf{2 0 0 4}$ & $4 / 9.8$ & 39 & 3.13 \\
$\mathbf{2 0 0 8}$ & $7 / 9.9$ & 69 & 2.50 \\
$\mathbf{2 0 1 2}$ & $2 / 8.5$ & 17 & 4.27 \\
& & & 2.29 \\
Summer 1971 & $2 / 5.5$ & 11 & 2.60 \\
$\mathbf{2 0 0 4}$ & $7 / 11.3$ & 80 & 1.75 \\
$\mathbf{2 0 0 8}$ & $3 / 9.7$ & 29 & 1.99 \\
$\mathbf{2 0 1 2}$ & $1 / 12$ & 12 & \\
\hline
\end{tabular}

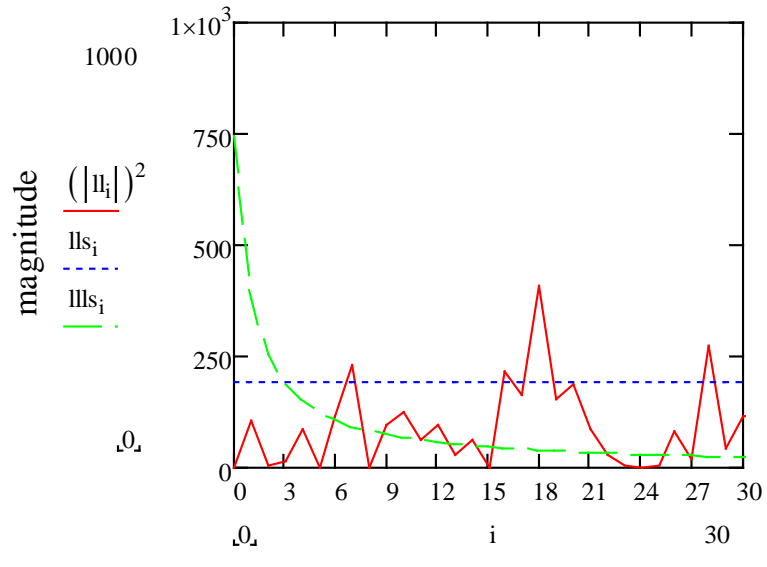

wave number

(a)

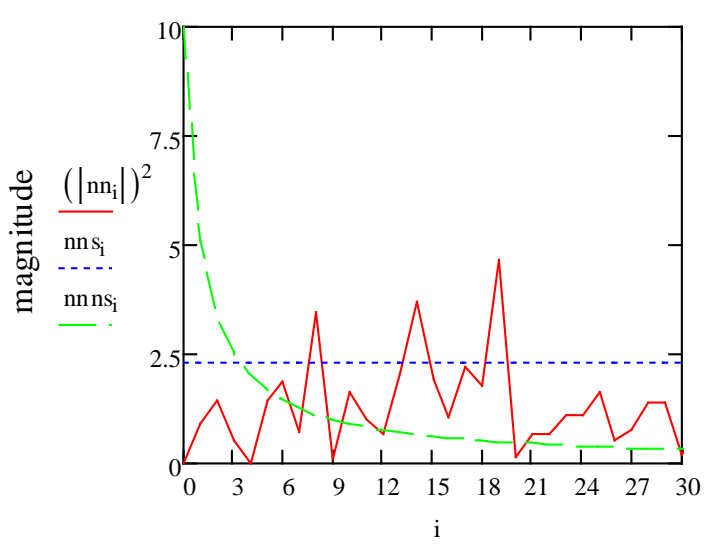

wave number

(b)

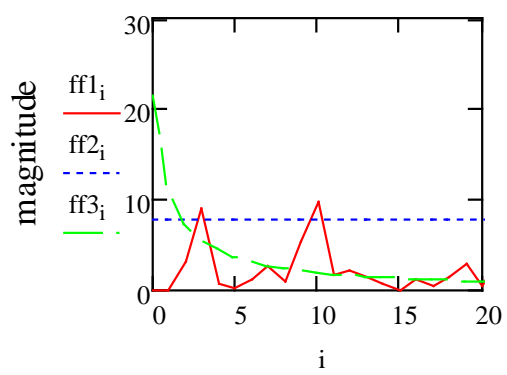

wave number

(c)

Figure 8. The power spectra versus wave number (per 67 years) for the (a) summer season temperatures, and (b) the final date time series from Figure 3(b). The blue (green) dotted line is the 95\% confidence level for a white (red) noise spectrum. (see Wilks, 2006). For (c) as in (a) and (b) except per 46 years for the occurrence of Pacific region summer blocking (from Figure 4(b)). 
wetter summers. Both 2004 and 2008 were cooler, wet summers, while 2012 was the least blocked season after 2000. This season was very hot and dry. Additionally 1980 was tied for the least blocked summer season for the entire period 1969-2014, and 1971 was about average for the summer temperatures, but quite dry. The regular occurrence of blocking would allow for more variable summer weather and more frequent intrusions of cooler air in the region. Separating the occurrence of blocking by ENSO phase would demonstrate that more blocking occurred in years in which the transition was toward the El Nino (2.4 events) than those when the transition was the other way (1.75 events).

The study of [2] found no statistically significant differences between the summer temperatures as a function of ENSO in their 20 year study. Table 9 shows the mean seasonal temperature for each case in Table 7 using the larger data set. Similar to [56] or [57], -PDO springs and summers show slight ENSO variation for spring and summer temperatures following El Niño onset averaging slightly warmer than summers following La Niña onset. This result matches the studies of [56] and similar studies from this group that there is weak ENSO variability in -PDO years. In +PDO yeas, which overlapped with most of the years in the [2] study, they found warmer summers following El Niño onset was statistically insignificant. Here we found that these summers were warmer at the $90 \%$ confidence level, but the spring-summer temperature difference is significantly larger at the 95\% confidence level. As in Ratley et al. [2], we can conclude that useful information may be found by relating the change in ENSO phase to summer temperatures, and [27] ([28]) found a similar phenomenon for a study of the summers of eastern (western) Russia, respectively.

In examining the changes in ENSO phase, defined as the difference between the new phase of 1 October and the phase of the current summer, [2] examined the tendencies for certain ENSO phase changes to be associated with early or late onsets. Here, we will define changes toward the La Niña (El Niño) direction as positive (negative), and no change in phase as a null case. Then, [2] found that positive (negative and null) transitions were associated with late (early) onsets. The results of our study indicate no such tendency in the much longer data set (Table 10). In fact it appears that all possible transitions are equally likely to produce early and late transitions overall.

Table 9. As in Table 7 except for mean spring and summer temperatures.

\begin{tabular}{cccc}
\hline ENSO phase & Spring $\left({ }^{\circ} \mathbf{C}\right)$ & Summer $\left({ }^{\circ} \mathbf{C}\right)$ & Difference $\left({ }^{\circ} \mathbf{C}\right)$ \\
\hline El Nino (15) & $12.5 / 12.8$ & $24.5 / 24.6$ & $12.0 / 11.8$ \\
Neutral (36) & $12.0 / 12.6$ & $24.2 / 24.5$ & $12.2 / 11.9$ \\
La Nina (16) & $11.9 / 12.2$ & $23.1 / 24.1$ & $11.2 / 11.9$ \\
\hline
\end{tabular}

Table 10. ENSO phase changes for early and late summer onset dates where a positive phase change is toward La Niña and negative is toward El Niño and null is no change in phase from one year to the next.

\begin{tabular}{ccc}
\hline Direction of phase change & Early & Late \\
\hline Positive & 2 & 5 \\
EL-Neu & 5 & 2 \\
EL-LA & 2 & 1 \\
NEU-LA & & \\
Null & 1 & 0 \\
EL-EL & 12 & 10 \\
NEU-NEU & 3 & 3 \\
LA-LA & & \\
Negative & 5 & 1 \\
LA-NEU & 3 & 1 \\
LA-EN & 4 & 7 \\
NEU-EN & 5
\end{tabular}


Finally, [2] found that summers associated with a transition toward La Niña or steady state La Niña conditions produced warmer, drier summers partly based on conjecture. Here, we tested all 67 seasonal transitions, and positive transitions were indeed warmest $\left(24.6^{\circ} \mathrm{C}\right)$, followed by null transitions $\left(24.2^{\circ} \mathrm{C}\right)$, and negative transitions $\left(24.0^{\circ} \mathrm{C}\right)$. This result is not statistically significant, but does support the assertions of [12] and [13] who also found La Niña transitions to be warmer. Narrowing the subset to include only El Niño (-) and La Niña (+) transitions and their null cases (back-to-back years) for both demonstrates that La Niña transitions and steady state La Niña years produced a mean temperature of $24.8^{\circ} \mathrm{C}$, versus $24.0^{\circ} \mathrm{C}$ for El Niño onsets and steady El Niño conditions. Including only La Niña or El Niño onsets and eliminating their null cases, the average summer temperature was $25.1^{\circ} \mathrm{C}$ versus $24.1^{\circ} \mathrm{C}$. Thus, the conclusion of [2] that transitions toward La Niña were warmer is valid, or even stronger, in the much larger dataset.

\section{Discussion}

The methodology of [2] for identifying the spring-to-summer transition was used for a longer dataset, this one covering a 68 year period from 1948-2015. They [2] used surface temperatures to derive a criterion based on the daily maximum and mean temperatures, and a $500 \mathrm{hPa}$ height map criterion with the goal of identifying the spring-to-summer transition date for a 20 year period. They used each criterion in order to determine a date that matched one of the three dates found by the available individual criterion. This study modified the practice and identified the mean date of the three available criteria as the spring-to-summer transition date. It was found that:

- the statistics produced by this study were similar to those produced by the [2] study for the spring-to-summer transition date, in that the $500 \mathrm{hPa}$ height mean transition date was the latest, and the maximum temperature mean transition date the earliest,

- the daily mean temperature criterion was the closest to the overall date (June 12) found by compiling the three criterion, it was only one day different in both this and the earlier study. This criterion and the final date were very strongly correlated, significant at the $99 \%$ confidence level.

- the mean spring temperatures trended upward at a significant rate, while the summer season temperatures were slightly cooler providing for a smaller annual cycle, and a significant trend (at the $99 \%$ confidence level) toward an earlier onset date,

- when comparing the results of this study to the smaller time period of the [2] work, it was found that our modification for identifying the final transition date had little impact on the overall statistics,

- Pacific region blocking showed a strong increase in occurrence and days, but not intensity, and more summer season blocking was associated with cooler summers and the transition toward El Niño,

- the $850 \mathrm{hPa}$ and $500 \mathrm{hPa}$ height fields show that the 30 day period before five chosen onset days was different from the 30 day period following onset. At the $500 \mathrm{hPa}$ level, the 582 contour was located over or equatorward of the region during the spring and poleward during the summer. At $850 \mathrm{hPa}$, the summer season flow was more meridional and during the drier years the strongest flow was to the west of the study region,

- the [2] study found that summer seasons preceding La Niña onset were warmer and the transition date was later that the mean. Here we found that the association of La Niña onset summers being hotter summers was confirmed and the result was stronger than that of the [2] finding. However, this study did not find a tendency for early or late summer onsets in association with ENSO,

- the IRE diagnostic used for example in [6] indicated that the dates chosen for the spring-to-summer transition were close to decreases in the northern hemisphere enstrophy demonstrating that the criterion proposed here has utility in identifying the seasonal transition,

- and finally, this study showed only slight interdecadal variability in ENSO behavior, unlike other studies of different variables and seasons for this region, in particular it was noted that ENSO summers in the -PDO phase were similar overall with little variation, while in the +PDO the summers following La Niña were cooler and associated with a smaller spring-to-summer temperature change.

\section{Conclusion}

In conclusion, these results would have applicability for seasonal or long-range forecasting in the region of study. The studies of [10] and [11] both demonstrate that SST anomalies and the occurrence of summer Pacific Region blocking correlate strongly to the summer weather and climate of the study region. These variables can then be used to predict the conditions of the summer season [11]. The information gained here provides another variable 
that can be used for long-range seasonal prediction, and this information should be on interest to the regional agriculture community.

\section{Acknowledgements}

The authors would like to thank Professor Neil I. Fox for his earlier comments on this work, as well as the anonymous reviewers who helped to make this a stronger contribution.

\section{References}

[1] Hansen, A.R. (1986) Observational Characteristics of Atmospheric Planetary Waves with Bimodal Amplitude Distributions. Advances in Geophysics, 29, 101-134. http://dx.doi.org/10.1016/S0065-2687(08)60036-9

[2] Ratley, C.W., Lupo, A.R. and Baxter, M.A. (2002) Determining the Spring to Summer Transition in the Missouri Ozarks Using Synoptic Scale Data. Transactions of the Missouri Academy of Science, 36, 55-62.

[3] Johns, R.H. (1993) Meteorological Conditions Associated with Bow Echo Development in Convective Storms. Weather and Forecasting, 8, 294-299.

[4] Higgins, W.R., Yao, Y. and Wang X.L. (1997) Influence of the North American Monsoon System on the United States Summer Precipitation Regime. Journal of Climate, 10, 2600-2622. http://dx.doi.org/10.1175/1520-0442(1997)010<2600:IOTNAM>2.0.CO;2

[5] Wang, S.Y. and Chen, T.C. (2009) The Late Spring Maximum of Rainfall over the U.S. Central Plains and the Role of the Low-Level Jet. Journal of Climate, 22, 4696-4709. http://dx.doi.org/10.1175/2009JCLI2719.1

[6] Jensen, A.D. and Lupo, A.R. (2013) Using Enstrophy Advection as a Diagnostic to Identify Blocking Regime Transition. Quarterly Journal of the Royal Meteorological Society, 139, 2-7. http://dx.doi.org/10.1002/qj.2248

[7] Lupo, A.R., Kelsey, E.P., McCoy, E.A., Halcomb, C.E., Aldrich, E.M., Allen, S.A., Akyuz, F.A., Skellenger, S., Bieger, D.G., Wise, E., Schmidt, D. and Edwards, M. (2003) The Presentation of Temperature Information in Television Broadcasts: What Is Normal? National Weather Digest, 27, 53-58.

[8] Spar, J. (1949) Energy Changes in the Mean Atmosphere. Journal of Meteorology, 6, 411-415. http://dx.doi.org/10.1175/1520-0469(1949)006<0411:ECITMA>2.0.CO;2

[9] Kung, E.C. and Chern, J.G. (1995) Prevailing Anomaly Patterns of the Global Sea Surface Temperatures and Tropospheric Responses. Atmósfera, 8, 99-114.

[10] Lupo, A.R., Kelsey, E.P., Weitlich, D.K., Mokhov, I.I., Akyuz, F.A., Guinan, P.E. and Woolard, J.G. (2007) Interannual and Interdecadal Variability in the Predominant Pacific Region SST Anomaly Patterns and Their Impact on a Local Climate. Atmósfera, 20, 171-196.

[11] Lupo, A.R., Kelsey, E.P., Weitlich, D.K., Davis, N.A. and Market, P.S. (2008) Using the Monthly Classification of Global SSTs and 500 hPa Height Anomalies to Predict Temperature and Precipitation Regimes One to Two Seasons in Advance for the Mid-Mississippi Region. National Weather Digest, 32, 11-33.

[12] Birk, K., Lupo, A.R. Guinan, P.E. and Barbieri, C.E. (2010) The interannual variability of Midwestern temperatures and precipitation as related to the ENSO and PDO. Atmósfera, 23, 95-128.

[13] Lupo, A.R., Smith, N.B., Guinan, P.E. and Chesser, M.D. (2012) The Climatology of Missouri Region Dew Points and the Relationship to ENSO. National Weather Digest, 36, 10-20.

[14] Walker, G.T. and Bliss, E.W. (1932) World Weather V. Memoirs of the Royal Meteorological Society, 4, 53-84.

[15] Grimm, A.M. and Tedeschi, R.G. (2009) ENSO and Extreme Rainfall Events in South America. Journal of Climate, 22, 1589-1609. http://dx.doi.org/10.1175/2008JCLI2429.1

[16] Muñoz, E., Wang, C. and Enfield, D. (2010) The Intra-Americas Springtime Sea Surface Temperature Anomaly Dipole as a Fingerprint of Remote Influences. Journal of Climate, 23, 43-56. http://dx.doi.org/10.1175/2009JCLI3006.1

[17] Zuki, Z.M. and Lupo, A.R. (2008) The Interannual Variability of Tropical Cyclone Activity in the Southern South China Sea. Journal of Geophysical Research, 113, D06106.

[18] Lupo, A.R., Latham, T.K., Magill, T., Clark, J.V., Melick, C.J. and Market, P.S. (2008) The Interannual Variability of Hurricane Activity in the Atlantic and East Pacific Regions. National Weather Digest, 32, 119-135.

[19] Fasullo, J. and Webster, P.J. (2002) Hydrological Signatures Relating the Asian Summer Monsoon and ENSO. Journal of Climate, 15, 3082-3095. http://dx.doi.org/10.1175/1520-0442(2002)015<3082:HSRTAS>2.0.CO;2

[20] Wu, R. and Kirtman, B.P. (2007) Roles of the Indian Ocean in the Australian Summer Monsoon ENSO Relationship. Journal of Climate, 20, 4768-4788. http://dx.doi.org/10.1175/JCLI4281.1

[21] Ropelewski, C.F. and Halpert, M.S. (1987) Global and Regional Scale Precipitation Patterns Associated with the El 
Niño/Southern Oscillation. Monthly Weather Review, 115, 1606-1626. http://dx.doi.org/10.1175/1520-0493(1987)115<1606:GARSPP>2.0.CO;2

[22] Ropelewski, C.F. and Halpert, M.S. (1989) Precipitation Patterns Associated with the High Index Phase of the Southern Oscillation. Journal of Climate, 2, 268-284. http://dx.doi.org/10.1175/1520-0442(1989)002<0268:PPAWTH>2.0.CO;2

[23] Bove, M.C., Elsner, J.B., Landsea, C.W., Niu, X. and O’Brien, J.J. (1998) Effects of El Niño on U.S. Landfalling Hurricanes, Revisited. Bulletin of the American Meteorological Society, 79, 2477-2482. http://dx.doi.org/10.1175/1520-0477(1998)079<2477:EOENOO>2.0.CO;2

[24] Shinker, J.J. and Bartlein, P.J. (2009) Visualizing the Large-Scale Patterns of ENSO-Related Climate Anomalies in North America. Earth Interactions, 13, 1-50. http://dx.doi.org/10.1175/2008EI244.1

[25] Mo, K.C. (2010) Interdecadal Modulation of the Impact of ENSO on Precipitation and Temperature over the United States. Journal of Climate, 23, 3639-3656. http://dx.doi.org/10.1175/2010JCLI3553.1

[26] Hu, Z.-Z. and Huang, B. (2009) Interferential Impact of ENSO and PDO on Dry and Wet Conditions in the U.S. Great Plains. Journal of Climate, 19, 5500-5518. http://dx.doi.org/10.1175/JCLI3923.1

[27] Mokhov, I.I., Khon, V.C., Timazhev, A.V., Chernokulsky, A.V. and Semenov, V.A. (2014) Hydrological Anomalies and Trends in the Amur River Basin Due to Climate Changes. In: Extreme Floods in the Amur River Basin: Causes, Forecasts, and Recommendations, Roshydromet, Earth Climate Theory Studies, 81-121.

[28] Lupo, A.R., Mokhov, I.I., Chendev, Y.G., Lebedeva, M.G., Akperov, M. and Hubbart, J.A. (2014) Studying Summer Season Drought in Western Russia. Advances in Meteorology, Special Issue: Large Scale Atmospheric Science, 2014, Article ID: 942027. http://dx.doi.org/10.1155/2014/942027

[29] Kalnay, E., et al. (1996) The NCEP/NCAR 40-Year Reanalysis Project. Bulletin of the American Meteorological Society, 77, 437-471. http://dx.doi.org/10.1175/1520-0477(1996)077<0437:TNYRP>2.0.CO;2

[30] Neter, J., Wasserman, W. and Whitmore, G.A. (1988) Applied Statistics. 3rd Edition, Allyn and Bacon Press, Boston, $1006 \mathrm{p}$.

[31] Wilks, D.S. (2006) Statistical Methods in the Atmospheric Sciences. 2nd Edition, Academic Press, San Diego, 627 p.

[32] Park, C.-K. and Kung, E.C. (1988) Principal Components of the North American Summer Temperature Field and the Antecedent Oceanic and Atmospheric Condition. Journal of the Meteorological Society of Japan, 66, 677-690.

[33] Lee, J.-W. and Kung, E.C. (2000) Seasonal-Range Forecasting of the Ozark Climate by a Principal Component Regression Scheme with Antecedent Seas Surface Temperatures and Upper Air Conditions. Atmósfera, 13, $223-244$.

[34] Palecki, M.A. and Leathers, D.J. (2000) Spatial Modes of Drought in the Central United States. Preprints of the 12th Conference on Applied Climatology, Asheville, 8-11 May 2000, 4 p.

[35] Renken, J.S., Herman, J., Parker, D., Bradshaw, T. and Lupo, A.R. (2015) Using the Bering Sea and Typhoon Rules to Generate Long Range Forecasts. 39th NOAA Annual Climate Diagnostics and Prediction Workshop, St. Louis, 20-23 October 2014, 46-50. http://weather.missouri.edu/gcc/39cdpwdigest.pdf

[36] Pielke, R.A. and Landsea, C.N. (1999) La Niña, El Niño and Atlantic Hurricane Damages in the United States. Bulletin of the American Meteorological Society, 80, 2027-2033. http://dx.doi.org/10.1175/1520-0477(1999)080<2027:LNAENO>2.0.CO;2

[37] Huang, D., Ni, X., Tang, Q., Zhu, X. and Xu, D. (2012) Spatial and Temporal Variability of Sea Surface Temperature in the Yellow Sea and East China Sea over the Past 141 Years. In: Wang, S.-Y. and Gillies, R.R., Eds., Modern Climatology, Chap. 8, Intech Open, East Providence, 213-234. http://dx.doi.org/10.5772/34236

[38] Hanley, D.E., Bourassa, M.A., O’Brien, J.J., Smith, S.R. and Spade, E.R. (2003) A Quantitative Evaluation of ENSO Indices. Journal of Climate, 16, 1249-1258. http://dx.doi.org/10.1175/1520-0442(2003)16<1249:AQEOEI>2.0.CO;2

[39] Mantua, N.J., Hare, S.R., Zhang, Y., Wallace, J.M. and Francis, R.C. (1997) A Pacific Interdecadal Climate Oscillation with Impacts on Salmon Production. Bulletin of the American Meteorological Society, 78, 1069-1079. http://dx.doi.org/10.1175/1520-0477(1997)078<1069:APICOW>2.0.CO;2

[40] Minobe, S. (1997) A 50 - 70-Year Climatic Oscillation over the North Pacific and North America. Geophysical Research Letters, 24, 683-686. http://dx.doi.org/10.1029/97GL00504

[41] Bentley, M.L. and Mote, T. (1998) A Climatology of Derecho-Producing Mesoscale Convective Systems in the Central and Eastern United States, 1986-1995. Part I: Temporal and Spatial Distribution. Bulletin of the American Meteorological Society, 79, 2527-2540. http://dx.doi.org/10.1175/1520-0477(1998)079<2527:ACODPM>2.0.CO;2

[42] Wang, S.-Y., Chen, T.-C. and Correia Jr., J. (2009) Climatology of Summer Midtropospheric Perturbations in the U.S. Northern Plains. Part I: Influence on Northwest Flow Severe Weather Outbreaks. Climate Dynamics, 31, 1221-1237.

[43] Swanson, K.L. (2001) Upper-Tropospheric Potential Vorticity Fluctuations and the Dynamic Relevance of the Time 
Mean. Journal of the Atmospheric Sciences, 58, 1815-1826. http://dx.doi.org/10.1175/1520-0469(2001)058<1815:UTPVFA>2.0.CO;2

[44] Lupo, A.R. and Bosart, L.F. (1999) An Analysis of a Relatively Rare Case of Continental Blocking. Quarterly Journal of the Royal Meteorological Society, 125, 107-138. http://dx.doi.org/10.1002/qj.49712555308

[45] Yarnal, B. (1993) Synoptic Climatology in Environmental Analysis. CRC Press, Boca Raton, 195 p.

[46] Namias, J. (1982) Anatomy of Great Plains Protracted Heat Waves (Especially the 1980 US Summer Drought). Monthly Weather Review, 110, 824-838. http://dx.doi.org/10.1175/1520-0493(1982)110<0824:AOGPPH>2.0.CO;2

[47] Namias, J. (1983) Some Causes of United States Drought. Journal of Applied Meteorology and Climatology, 22, 30-39. http://dx.doi.org/10.1175/1520-0450(1983)022<0030:SCOUSD>2.0.CO;2

[48] Dymnikov, V.P., Kazantsev, Y.V. and Kharin, V.V. (1992) Information Entropy and Local Lyapunov Exponents of Barotropic Atmospheric Circulation. Izvestiya, Atmospheric and Oceanic Physics, 28, 425-432.

[49] Hurrell, J.W., van Loon, H. and Shea, D.J. (1998) Meteorology of the Southern Hemisphere. NCAR Tech. Memo. NCAR/CAS/95-08, 77 p.

[50] IPCC (2013) Climate Change 2013: The Physical Scientific Basis, Contributions of Working Group I to the Fifth Assessment Report of the Intergovernmental Panel on Climate Change. http://www.ipcc.ch

[51] Lupo, A.R., Smith, P.J. and Zwack, P. (1992) A Diagnosis of the Development of Two Extratropical Cyclones. Monthly Weather Review, 120, 1490-1523. http://dx.doi.org/10.1175/1520-0493(1992)120<1490:ADOTED>2.0.CO;2

[52] Wiedenmann, J.M., Lupo, A.R., Mokhov, I.I. and Tikhonova, E. (2002) The Climatology of Blocking Anticyclones for the Northern and Southern Hemisphere: Block Intensity as a Diagnostic. Journal of Climate, 15, 3459-3473. http://dx.doi.org/10.1175/1520-0442(2002)015<3459:tcobaf>2.0.co;2

[53] Quiroz, R.S. (1984) The Climate of the 1983-1984 Winter. A Season of Strong Blocking and Extreme Cold in North America. Monthly Weather Review, 112, 1894-1912. http://dx.doi.org/10.1175/1520-0493(1984)112<1894:TCOTWS>2.0.CO;2

[54] Jensen, A.D. (2015) A Dynamic Analysis of a Record Breaking Winter Season Blocking Event. Advances in Meteorology, Special Issue: Large-Scale Dynamics, Anomalous Flows, and Teleconnections, 2015, Article ID: 634896.

[55] Lupo, A.R. and Market, P.S. (2002) The Verification of Weather Forecasts in Central Missouri and Seasonal Variations in Forecast Accuracy. Weather and Forecasting, 8, 891-897.

[56] Berger, C.L., Lupo, A.R., Browning, P., Bodner, M., Rayburn, C.C. and Chambers, M.D. (2003) A Climatology of Northwest Missouri Snowfall Events: Long Term Trends and Interannual Variability. Physical Geography, 14, 427448.

[57] Lupo, A.R., Albert, D., Hearst, R., Market, P.S., Akyuz, F.A. and Allmeyer, C.L. (2005) Interannual Variability of Snowfall Events and Snowfall-to-Liquid Water Equivalents in Southwest Missouri. National Weather Digest, 29, 1324. 